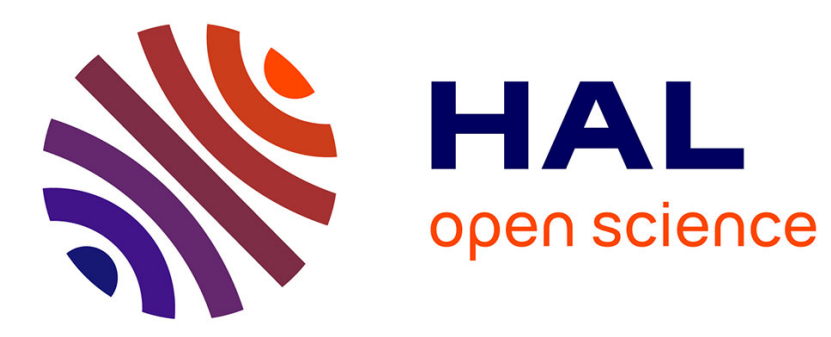

\title{
Modeling strain and anisotropy along the Alpine fault, south Island, New Zealand
}

\author{
M. Savage, Andrea Tommasi, S. Ellis, Jean Chery
}

\section{To cite this version:}

M. Savage, Andrea Tommasi, S. Ellis, Jean Chery. Modeling strain and anisotropy along the Alpine fault, south Island, New Zealand. David Okaya; Tim Stern; Fred Davey. A continental plate boundary: tectonics of South Island New Zealand, 175, AGU, pp.289-305, 2007, Geophysical Monograph Series, 10.1029/175GM15 . hal-00408272

\section{HAL Id: hal-00408272 \\ https://hal.science/hal-00408272}

Submitted on 21 Feb 2022

HAL is a multi-disciplinary open access archive for the deposit and dissemination of scientific research documents, whether they are published or not. The documents may come from teaching and research institutions in France or abroad, or from public or private research centers.
L'archive ouverte pluridisciplinaire HAL, est destinée au dépôt et à la diffusion de documents scientifiques de niveau recherche, publiés ou non, émanant des établissements d'enseignement et de recherche français ou étrangers, des laboratoires publics ou privés.

\section{다)(1) $(5$}

Distributed under a Creative Commons Attribution - NonCommerciall 4.0 International 


\title{
Modeling Strain and Anisotropy Along the Alpine Fault, South Island, New Zealand
}

\begin{abstract}
M. K. Savage ${ }^{1}$, A. Tommasi, ${ }^{2}$ S. Ellis ${ }^{3}$, and J. Chery ${ }^{2}$
Near-surface deformation between the Australian and Pacific plates in South Island, New Zealand is concentrated in a narrow zone marked by the Alpine Fault, but strong and widespread anisotropy inferred across New Zealand from shear wave splitting suggests diffuse deformation at mantle depths. To constrain this interpretation, we calculate temperature- and stress-dependent strain fields, crystal preferred orientation, anisotropy and resultant shear-wave splitting beneath a lithospheric fault deforming by either pure strike-slip or transpression. In pure strike-slip experiments, strain localizes in the high temperature regions under the thick continental landmass. Under the oceanic regions, which have thin crust, anisotropy is weak (delay times (dt) $<0.5 \mathrm{~s}$ for a $100 \mathrm{~km}$ thick lithosphere). Under the continents, dt increases to $1.0 \mathrm{~s}$ for $100 \mathrm{~km}$ and $2.3 \mathrm{~s}$ for $200 \mathrm{~km}$ thick lithosphere. Dt saturates before $15 \mathrm{My}$ (525 km displacement), at which point the polarizations of the first arriving shear waves $(\phi)$ are $25^{\circ}$ from fault-parallel, similar to measurements in southern South Island. Further strain does not increase dt, but $\phi$ rotates to $15^{\circ}$ from fault-parallel for displacements $>1400 \mathrm{~km}$. In transpression experiments that have initial structure based on estimates of the present crustal thickness and temperature, the cold root inhibits strain beneath the fault and leads to anisotropy patterns that do not explain the observations. This suggests that (a) a weak zone in the mantle lithosphere is needed to explain present-day deformation; and (b) most of the anisotropy measured may be "frozen in" from strike-slip deformation that occurred before the present mantle root developed.
\end{abstract}

\section{INTRODUCTION}

In central South Island, New Zealand, over $70 \%$ of the relative motion between the Pacific and Australian plates is currently accommodated along the Alpine Fault [e.g., Norris

${ }^{1}$ Institute of Geophysics, School of Earth Sciences, Victoria University of Wellington, New Zealand

${ }^{2}$ University de Montpellier II, France

${ }^{3}$ GNS Science, New Zealand and Cooper, 2001, and references therein]. Yet strong anisotropy inferred across the width of New Zealand from shear wave splitting [Molnar et al., 1999] and Pn phases [Baldock and Stern, 2005] has been cited as evidence that the mantle undergoes diffuse deformation over length-scales of hundreds of kilometers (Figure 1). The anisotropy is assumed to be generated in the lithospheric mantle. Modeling of the deformation of a thin elastic lid above a broad shear zone embedded in an elastic half space [Moore et al., 2002] can fit both the surface deformation measured by GPS and the shear wave splitting data, although the fit is quite non-unique [e.g., Ellis et al., 2006]. Furthermore, crustal deformation has been measured away from the fault, and the close similarity between the fast polarizations from shear-wave splitting and the maximum extension determined structurally has 


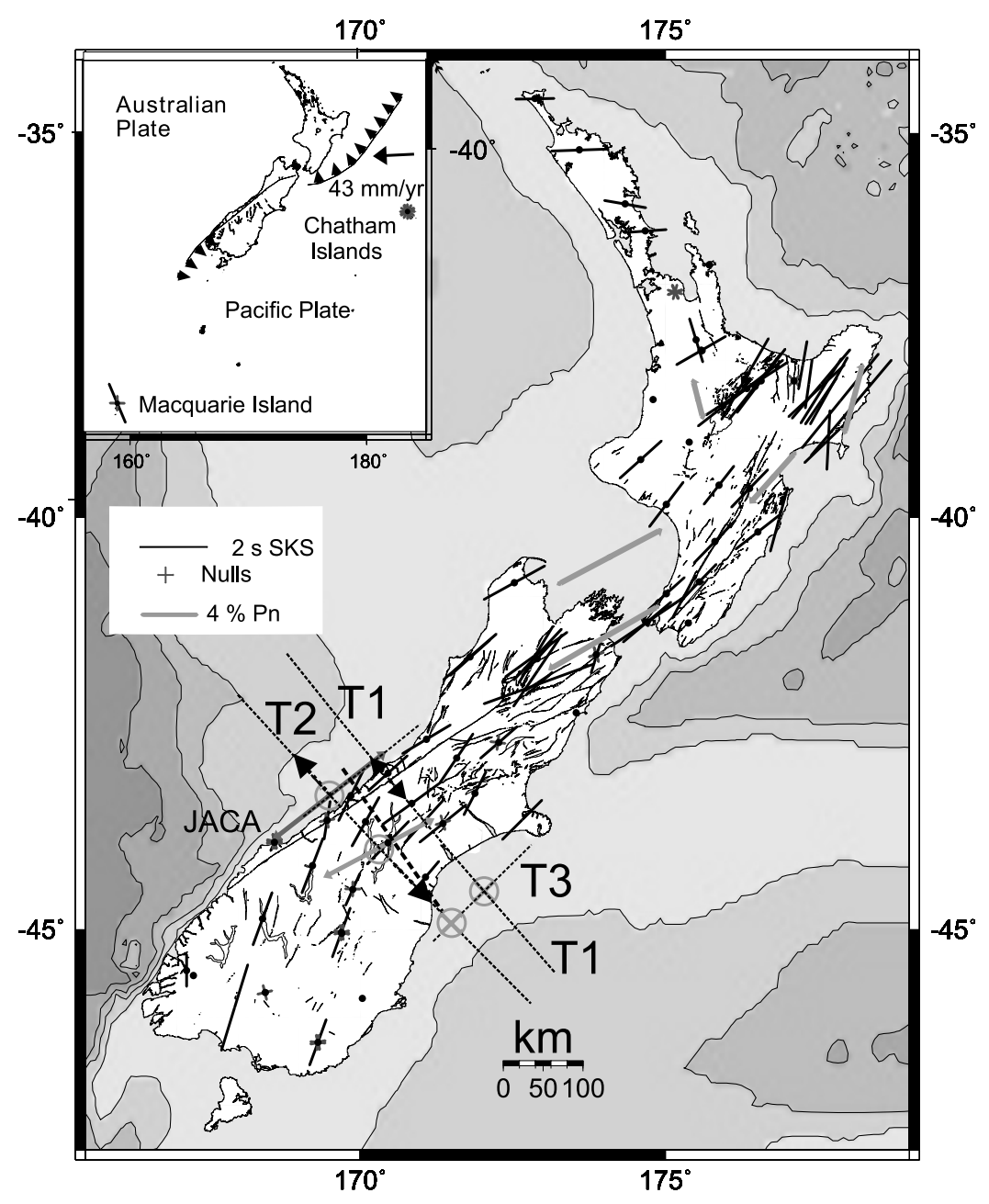

Figure 1. Seismic anisotropy measurements in New Zealand from Pn and SKS splitting, with bathymetry in $1000 \mathrm{~m}$ contours. Small filled circles: seismic stations on which SKS splitting has been analyzed. Bars: Positive measurements of splitting. Orientation of the line represents average fast polarization measured at the station, and length of the line is proportional to the average delay time as given in the scale. Crosses: null measurements (in which no splitting was observed), with the possible orientations that could yield no splitting. From Duclos [2005] and references therein. Gray arrows: Pn anisotropy, oriented along the line in which the fastest speed was measured. Length is proportional to anisotropy percentage as in the scale. Gray circles enclose the intersections of the lines used for the Pn measurements reported by Baldock and Stern [2005]; Bourguignon et al. [2007] and Scherwath et al. [2002]. Cross within the circle represents the lack of anisotropy measured by Baldock and Stern [2005] at the intersection of Lines T1 and T3. Other Pn measurements from regional earthquakes according to Smith and Ekstrom [1999]. Large arrows are the inferred limits of Pn anisotropy determined by the change in Pn along the SIGHT lines T1 and T2 [Scherwath et al., 2002; Baldock and Stern, 2005] Inset: Regional plate tectonic setting of NZ, and splitting measurements at nearby oceanic islands. The line on South Island is the Alpine Fault. Arrow represents present Pacific plate motion vector relative to the Australian Plate [Kreemer et al., 2003]. Chatham Islands splitting measurements were all null, suggesting no anisotropy in the horizontal plan. Color version of this figure is on CDROM which accompanies this volume.

been used to suggest that there is strong coupling between the crust and the mantle, with coherent deformation between the two [Little et al., 2002]. Worldwide studies also suggest that strong crust-mantle coupling may be widespread beneath major strike-slip faults [Silver, 1996; Tommasi et al., 1999].
Most measurements of seismic anisotropy come from shear-wave splitting of SKS phases. Shear wave splitting, or birefringence, occurs when shear waves impinge on an anisotropic medium. One component travels faster than the other, nearly orthogonal component. The polarization of the first shear arrival yields the fast orientation, and the time 
delay between the two components gives information about the strength of anisotropy combined with the length of the anisotropic path. SKS phases are difficult to use to constrain the depth extent of anisotropy, since the measured splitting may result from anisotropy anywhere along the path between the core mantle boundary and the surface [e.g., Savage, 1999]. The strength of anisotropy may vary with depth. Variations in fast orientations based on shear wave splitting measurements from local earthquakes in northern South Island, suggest that the uppermost mantle anisotropy is more localized than the SKS results suggest [Audoine et al., 2000]. Also, coherence of splitting measurements between North and South Islands hints that some of the anisotropy beneath New Zealand results from asthenospheric flow rather than lithospheric strain.

To better understand the origin of the anisotropy, strain can be calculated using geodynamic models, and resultant shear wave splitting computed to compare to observations [Blackman et al., 1996]. In a previous study, we used twodimensional geodynamic models with simple linear rheologies and kinematic boundary conditions to calculate strain; we then assumed simplified relations between the strain and anisotropy to evaluate the effects of strike-slip deformation on splitting measurements in California and New Zealand [Savage et al., 2004]. The New Zealand seismic anisotropy could be explained by strong coupling between the crust and mantle. These models therefore supported the suggestions of Moore et al., [2002] and Little et al., [2002] that the change in fast polarisations from between ca. $30^{\circ}$ to fault-parallel in southern South Island to fault-parallel in central South Island are caused by smaller strain to the south. However, the relationship between strain and delay time assumed in the modeling did not explain the constant delay times across the island, unless the delay times saturated at smaller strains than assumed.

Here we use more sophisticated models of both strain and anisotropy. Strain is calculated using an elasto-viscoplastic finite element model with a temperature- and stress-dependent viscosity [Chéry et al., 2004], in which full mechanical evolution is allowed. We then calculate the crystal preferred orientations formed in olivine-pyroxene aggregates in response to this strain field using a polycrystal plasticity approach [Tommasi et al., 2000] and the resulting elastic constants [Mainprice, 1990]. Ray-tracing through these models allows evaluation of the resulting shear wave splitting. We will show that these models better predict the anisotropy in South Island, in the sense that the delay times saturate at smaller strains than previously expected. We will further show that the formation of a cold lithospheric root, which has been interpreted from thermal modeling [Shi et al., 1996] and from measurements of early arrivals from teleseismic earthquakes with paths traveling through the root region [Stern et al., 2000; Kohler and Eberhart-Phillips, 2002], inhibits strain and anisotropy formation beneath the fault. Therefore, it is likely that the anisotropy measured in the vicinity of the Alpine Fault was formed during the strikeslip deformation period, before compressional deformation formed a cool root.

\section{METHOD}

\section{Geodynamic Modeling}

We use the 3D finite element (FE) code Adeli3D (version 3d4, [Chéry et al., 2004]) to investigate both the long-term evolution of the Southern Alps and the present deformation. Adeli3D solves for the quasi-static mechanical behavior of the lithosphere using an explicit scheme based on the Dynamic Relaxation Method [Cundall, 1988]. The model is not thermally coupled, but an initial temperature field is prescribed, which is then advected along with material points. We approximate the 3D plate boundary deformation in central South Island by prescribing a thin cross-sectional slice perpendicular to the Alpine Fault as an out-of-plane model, so that velocities are assumed not to vary along-strike, even though they change with distance and depth across-strike. This approximation allows us to use an unstructured mesh with an average element length-scale of $5 \mathrm{~km}$.

Both crust and mantle lithosphere are assumed to have an elasto-visco-plastic rheology with constant elastic strength, pressure-dependent yield, and thermally-activated viscous creep with either linear or non-linear viscous flow laws, (parameter values described in Tables 1 and 2). Frictional behavior follows a standard Drucker-Prager yield relationship:

$$
\begin{gathered}
f(\sigma)=J_{2}(\sigma)-\alpha\left[\bar{\sigma}+\frac{c}{\tan \phi_{0}}\right]<0 \\
J_{2}(\sigma)=\sqrt{\frac{3}{2}} \sqrt{\operatorname{dev} \sigma: \operatorname{dev} \sigma} \\
\alpha=\frac{6 \sin \phi_{0}}{3-\sin \phi_{0}} \\
\bar{\sigma}=-\frac{1}{3} \operatorname{tr}(\sigma)
\end{gathered}
$$

where $\sigma$ is the stress tensor, $\bar{\sigma}$ is the mean stress, dev is the deviatoric part of a tensor, and the colon represents the contracted product. $\phi_{0}$ is internal angle of friction, and $\mathrm{c}$ is cohesion [Leroy and Ortiz, 1989]. The dilatancy angle is set to zero, therefore leading to a non-associated plastic flow 
Table 1. Material properties used in the experiments

\begin{tabular}{|c|c|c|c|c|}
\hline Material & Density $\left(\mathrm{kg} \mathrm{m}^{-3}\right)$ & $\begin{array}{l}\text { ELASTIC: } \\
\text { Young's } \\
\text { modulus (Pa), } \\
\text { Poisson's ratio }\end{array}$ & $\begin{array}{l}\text { FRICTIONAL: } \\
\phi_{0}, \mathrm{C}(\mathrm{MPa})\end{array}$ & $\begin{array}{l}\text { VISCOUS: } \\
\gamma\left(\mathrm{Pa}^{-\mathrm{n}} \mathrm{s}^{-1}\right), \mathrm{E}_{\mathrm{a}}\left(\mathrm{KJ} \mathrm{mol}^{-1}\right), \mathrm{n}\end{array}$ \\
\hline Crust & 2800 & $1 \times 10^{11}, 0.25$ & $15^{\circ}, 1$ & $\begin{array}{l}3.28 \times 10^{-19}, 44,1 \text { or } 1.63 \times 10^{-26} \text {, } \\
135,3.1 \text { (nonlin) }\end{array}$ \\
\hline Fault & 2800 & $1 \times 10^{11}, 0.25$ & $3^{\circ}, 1$ & $\begin{array}{l}3.28 \times 10^{-19}, 44,1 \text { or } 1.63 \times 10^{-26} \text {, } \\
135,3.1 \text { (nonlin) }\end{array}$ \\
\hline $\begin{array}{l}\text { Strong } \\
\quad \text { Mantle }\end{array}$ & $\begin{array}{l}3300 \text { or eqn }(3) \\
\quad(\text { dens })\end{array}$ & $1 \times 10^{11}, 0.25$ & $15^{\circ}, 1$ & $\begin{array}{l}8.2 \times 10^{-18}, 111,1 \text { or } 7.24 \times 10^{-18}, \\
535,3.5 \text { (nonlin) }\end{array}$ \\
\hline $\begin{array}{l}\text { Weak } \\
\text { Mantle }\end{array}$ & $\begin{array}{l}3300 \text { or eqn }(3) \\
(\text { dens })\end{array}$ & $1 \times 10^{11}, 0.25$ & $15^{\circ}, 1$ & $16.4 \times 10^{-18}, 111,1$ \\
\hline
\end{tabular}

(the plastic potential is simply equal to $J_{2}(\sigma)$ ). For most of the materials in the numerical experiments, we use $\phi_{0}=15^{\circ}$. We also include a frictionally weak zone with $\phi_{0}=3^{\circ}$ to represent the strained, weakened brittle part of the Alpine Fault, dipping at $45^{\circ}$ in most experiments but vertical in some of the experiments.

Thermally-activated creep obeys the following relationship [e.g., Turcotte and Schubert, 1982]:

$$
\dot{\varepsilon}_{i j}=\gamma \tau_{i j}{ }^{n} \exp \left(-E_{a} / R T\right)
$$

where $\gamma$ is the fluidity in $\mathrm{Pa}^{-\mathrm{n}} \mathrm{s}^{-1}, \dot{\varepsilon}_{i j}, \tau_{i j}$ are the deviatoric $\mathrm{i}$-jth component of the strain-rate and stress tensors, respectively, $n$ is the power-law exponent, $E_{a}$ the activation energy, $R$ the gas constant, and $T$ is temperature in Kelvin. Creep parameters in the crust and mantle are chosen to approximate the behavior of hydrous quartz and dry olivine in high-temperature laboratory experiments [Chopra and Paterson, 1984; Paterson and Luan, 1990]. The strong anisotropy measured in New Zealand implies that dislocation creep, which is characterized by a non-linear stress-strain rate relation, is the dominant deformation mechanism in the shallow mantle beneath New Zealand, since diffusion creep does not produce crystal preferred orientations and hence no large-scale anisotropy develops. However, some numerical experiments were run with a linear relation between stress and strain (Newtonian behavior; $n=1$ ) because the results were numerically more stable than for nonlinear rheologies. The linear viscous parameter values were chosen to approximate the experimentally observed non-linear behavior for a representative temperature gradient and strain-rate. Linearized rheologies thus have $E_{a}$ and $\gamma$ recalculated in order to produce the same viscosity of the actual dislocation creep law at similar temperatures for a constant strain-rate of $4 \times 10^{-15} \mathrm{~s}^{-1}$.
In some experiments we also applied a ductile strainsoftening in the mantle, where the fluidity is multiplied by $(0.2)^{-\mathrm{n}}$ for finite strains larger than 1 . These experiments yielded little differences in the final strain distribution and shear-wave splitting values from the cases without strainsoftening.

In some experiments (those with suffix dens in Table 3), we also tested the effect of a temperature-dependent density in the mantle. In this case, mantle density obeys the following function [Turcotte and Schubert, 1982]:

$\rho=\left(\frac{\rho_{0}}{1-\rho_{0} g z \beta_{a}}\right)\left(1-\Delta T \alpha_{V}\right)$

where $\rho_{0}$ is the initial density $\left(3300 \mathrm{~kg} / \mathrm{m}^{3}\right.$ for the mantle), $g$ is the acceleration of gravity (assumed $-10 \mathrm{~ms}^{-2}$ ), $z$ is the depth below sea level, $\beta_{a}$ is the adiabatic compressibility, (assumed $8.7 \times 10^{-12} \mathrm{~Pa}^{-1}$ ), $\Delta T$ is the temperature difference between the true temperature and a reference temperature (chosen as $1223^{\circ} \mathrm{K}$, the temperature at $50 \mathrm{~km}$ depth), and $\alpha_{V}$ is the coefficient of thermal expansion at constant volume (assumed to be $3 \times 10^{-5} \mathrm{~K}^{-1}$ ).

\section{Lattice Preferred Orientation From Polycrystal Plasticity Models}

The development of olivine and orthopyroxene lattice preferred orientations (LPO) as a function of strain is calculated using a viscoplastic self-consistent model [Lebensohn and Tomé, 1993]. This model simulates the LPO evolution due to plastic deformation by dislocation glide in a bimodal $(60 \%$ olivine $-40 \%$ enstatite) polycrystalline material. In polycrystal plasticity models, LPO evolution is essentially controlled by the imposed deformation, the initial texture (crystal preferred and, to a lesser extent, shape preferred orientation), and the active slip systems. The latter depend 
Table 2. Viscoplastic model slip systems' data

\begin{tabular}{lccc}
\hline Mineral & Slip system & CRSS & $\mathrm{n}$ \\
\hline olivine & $(010)[100]$ & 1 & 3 \\
& $(001)[100]$ & 1 & 3 \\
& $(010)[001]$ & 2 & 3 \\
enstatite & $(100)[001]$ & 3 & 3 \\
& $(100)[001]$ & 2 & 3 \\
& $(010)[001]$ & 5 & 3 \\
\hline
\end{tabular}

on the mineral structure, but also on the temperature and pressure conditions, which control their relative strength or critical resolved shear stress. In order to simulate olivine and pyroxene LPO evolution in the lithospheric mantle and asthenosphere, we used, as in previous viscoplastic selfconsistent simulations for olivine [Wenk et al., 1991; Tommasi et al., 2000], slip system data (Table 2) derived from high-temperature, low-pressure single-crystal deformation experiments [Bai et al., 1991]. Higher critical resolved shear stresses for enstatite account for its higher strength relative to olivine.

The deformation history is derived directly from the final velocity gradient field in the mechanical model by assuming that for times $>100 \mathrm{ky}$, i.e., after the relaxation of elastic stresses, the flow pattern in the mantle does not change significantly. This allows us to calculate the anisotropy for times that are longer than those used in the geodynamic models, which become unstable when they become too deformed. To reduce calculation times, we avoid calculating the LPO evolution in neighboring elements with similar deformation histories. Instead, we search over the entire finite-element model and create velocity gradient tensor "classes". Within each class, variations for each of the tensor components are less than $5 \times 10^{-16} \mathrm{~s}^{-1}$. Olivine and enstatite LPO evolution are then calculated for each velocity gradient tensor "class". These LPO are used to compute the aggregate seismic properties based on a Voigt-Reuss-Hill average of the elastic constants of olivine and enstatite at ambient conditions [Kumazawa and Anderson, 1969; Mainprice, 1990]. The calculated LPO and elastic constant tensor are then tracked

Table 3. Summary

\begin{tabular}{|c|c|c|c|c|}
\hline Experiment Name run & Description & $\begin{array}{c}\text { Extent of Weak mantle } \\
(\mathrm{km} \text { from fault }) \text { at } \\
0 \mathrm{My}\end{array}$ & Temp & Motion \\
\hline $\begin{array}{l}\text { PASTTR, PASTTRnonlin } \\
\text { used in paper for Plate 1a,c,e, } \\
\text { and Figure } 2\end{array}$ & $\begin{array}{c}\text { Pre-root continent } \\
\text { Alpine Fault dips } 45^{\circ} \\
\text { No strain-softening } \\
\text { Mantle extends to } 100 \mathrm{~km} \text {. }\end{array}$ & none & Linear Gradient & $\begin{array}{l}35 \mathrm{~mm} / \mathrm{yr} \\
\text { along-fault } \\
10 \mathrm{~mm} / \mathrm{yr} \\
\text { across-fault }\end{array}$ \\
\hline $\begin{array}{l}\text { PRESTR, PRESTRnonlin } \\
\text { used in paper for Plate } 1 \mathrm{~b}, \mathrm{~d}, \mathrm{f} \text { and } \\
\text { Figure } 2\end{array}$ & $\begin{array}{l}\text { Root [Scherwath et al., } \\
\text { 2003] } \\
\text { Alpine Fault dips } 45^{\circ} \text {. } \\
\text { No strain-softening } \\
\text { Mantle extends to } 100 \mathrm{~km} \text {. }\end{array}$ & none & Shi et al., 1996 & same \\
\hline $\begin{array}{l}\text { PASTSS, PASTSSnonlin } \\
\text { Used in paper for Plate } 1 \mathrm{~h}, \\
\text { Figures } 2 \text { and } 3\end{array}$ & $\begin{array}{l}\text { Pre-root continent. } \\
\text { Alpine Fault vertical } \\
\text { Strain-softening used. } \\
\text { Mantle extends to } 100 \mathrm{~km} \text {. }\end{array}$ & none & Linear Gradient & $\begin{array}{l}35 \mathrm{~mm} / \mathrm{yr} \\
\text { along-fault } 0 \\
\text { across-fault }\end{array}$ \\
\hline $\begin{array}{l}\text { PASTSSdeep, PASTSSdeepnonlin } \\
\text { Used in paper for Figure } 3\end{array}$ & $\begin{array}{l}\text { Same as above but mantle } \\
\text { extends to } 200 \mathrm{~km} .\end{array}$ & none & Linear Gradient & $\begin{array}{l}\text { same as } \\
\text { above }\end{array}$ \\
\hline $\begin{array}{l}\text { PRESTRdensdeep, } \\
\text { PRESTRdensdeepnonlin } \\
\text { Used in paper in Plate } 2 \text { and } \\
\text { Figure } 4 .\end{array}$ & $\begin{array}{l}\text { Root [Scherwath et al., } \\
\text { 2003]. } \\
\text { Alpine Fault dips } 45^{\circ} \text {. } \\
\text { No strain-softening } \\
\text { Mantle extends to } 200 \mathrm{~km} \text {. }\end{array}$ & $-195 \mathrm{~km}$ to $150 \mathrm{~km}$ & Shi et al., 1996 & $\begin{array}{c}35 \mathrm{~mm} / \mathrm{yr} \\
\text { along-fault } \\
10 \mathrm{~mm} / \mathrm{yr} \\
\text { across-fault }\end{array}$ \\
\hline $\begin{array}{l}\text { PASTTRdens, PASTTRdensnonlin } \\
\text { Used in paper in Plate } 2 \text { and } \\
\text { Figure } 4\end{array}$ & $\begin{array}{l}\text { Pre-root continent. } \\
\text { Alpine Fault vertical } \\
\text { No strain-softening } \\
\text { Mantle extends to } 100 \mathrm{~km} \text {. } \\
\text { No erosion }\end{array}$ & $-20 \mathrm{~km}$ to $35 \mathrm{~km}$ & linear & $\begin{array}{l}35 \mathrm{~mm} / \mathrm{yr} \\
\text { along-fault } \\
10 \mathrm{~mm} / \mathrm{yr} \\
\text { across-fault }\end{array}$ \\
\hline
\end{tabular}


back to the final positions of the elements' baricenters in the finite-element model.

\section{Splitting Calculation}

To calculate shear-wave splitting, we modify a method outlined previously [Fischer et al., 2000]. Seismic ray paths are traced through the AK135 average global velocity model [Kennett et al., 1995] to determine which blocks of the model the ray passes through. A linear particle motion with a period of $10 \mathrm{~s}$ is passed through the first block and split using the Christoffel equation with the tensor of elastic coefficients calculated from the LPO models. The Christoffel equation gives the wave speeds and polarizations of the quasi $\mathrm{P}$ and two quasi $\mathrm{S}$ waves propagating through the medium with the given direction [Babuska and Cara, 1991]. The resultant particle motion is split again in the next block, and so on until the top of the model is reached. The net effects of splitting observed at the surface are measured using the same type of particle motion analysis [Silver and Chan, 1991] that is typically applied to real data.

\section{GEODYNAMIC EXPERIMENTS}

We consider two experimental setups (Table 3). The first, with labels starting by PAST, has initial conditions representing the time just before motion on the central Alpine Fault changed from nearly pure strike-slip to transpressional, at either 6.4 Ma [Walcott, 1998] or 11 Ma [Cande and Stock, 2004]. It uses a flat topography on the continental region, with crustal thickness of $27 \mathrm{~km}$ (see arguments in Stern et al., [2002]) from a distance of $200 \mathrm{~km}$ west of the Alpine fault to $230 \mathrm{~km}$ east of the fault [Scherwath et al., 2003]. East and west of the continental material, we use an oceanic Moho depth of 14.5 and $17 \mathrm{~km}$, respectively. Experiments in which we apply transpression are labeled PASTTR, and when we apply strike-slip, they are called PASTSS. PASTTR experiments impose a weak zone dipping at $45^{\circ}$ in the crust (to $27 \mathrm{~km}$ depth), representing the proto-Alpine Fault, and PASTSS experiments impose a vertical weak zone through the crust. We use a laterally uniform geotherm, based on the background temperature profile of Shi et al., [1996] for shallow depths $(\leq 50 \mathrm{~km})$ and a steeper thermal gradient in the deep lithosphere (Plate 1).

The second experiment setup, labeled PRESTR (Table 3), simulates the present situation. It uses a recent crustal structure model [Scherwath et al., 2003]. Note that this model has a slightly thicker oceanic crust on the east, while a seismic line about $50 \mathrm{~km}$ to the north reveals a slightly thicker oceanic crust to the west [van Avendonk et al., 2004]. The initial temperature profile is based on the temperature field obtained by finite element modeling of the compressional component of Alpine Fault motion [Shi et al., 1996], which is extrapolated to $100 \mathrm{~km}$ depth. Other initial temperature structures, like the one presented in Figure 6 of Stern et al., [2000], were also tested. However, due to space limitations, the results of these additional models are not shown here, since they do not yield more insight than the PRES experiments.

Most experiments were run with a model thickness of only $100 \mathrm{~km}$. However, several experiments with thicknesses of $200 \mathrm{~km}$ (suffix deep, Table 3) were run to test that model thickness did not significantly affect results.

In all experiments, we apply a lithostatic pressure condition at the base of the model. The upper boundary is free and gravity forces are fully taken into account. Both PAST and PRES model experiments start from geostatic equilibrium, attained by applying an initial one-dimensional lithostatic stress state and then allowing the experiments to equilibrate stresses over a short time interval. Velocity conditions mimicking the Pacific plate motion relative to Australia are applied on the Pacific side boundary of the model. The Australian side boundary is kept fixed. The actual plate motion has changed over time [Cande and Stock, 2004]. Thus two types of lateral boundary conditions were implemented: pure strike-slip experiments, in which we impose a $35 \mathrm{~mm} / \mathrm{yr}$ displacement of the southeastern boundary parallel to the fault (models with prefix PASTSS), and transpressional experiments, which have both a strike-slip component of $35 \mathrm{~mm} / \mathrm{yr}$ and a compressional component of $10 \mathrm{~mm} / \mathrm{yr}$ (experiments with prefix PRESTR and PASTTR).

\section{RESULTS}

Plate 1 shows the temperature and strain profiles for transpressional experiments PASTTR, which starts from the continental crust and mantle temperature profile assumed to occur before compression, and PRESTR, which uses the present temperature field and crustal structure (Table 3). For experiment PASTTR at $0 \mathrm{My}$, before any compression has taken place, the temperature is slightly higher under the continental than the oceanic mass. This is consistent with the expected warmer temperatures due to the crustal heat production and blanketing effect in the continental lithosphere. For experiment PRESTR, the temperature is colder under the Alpine Fault due to the localized crustal and mantle thickening (root). After 5 My of transpressive deformation, the temperatures under the continental mass in experiment PASTTR have decreased relative to those under the ocean, because the compressional component of motion induced thickening leading to displacement of cooler shallow material to deeper levels. In the crust, the deformation is localized within the weak (low friction) Alpine Fault block 

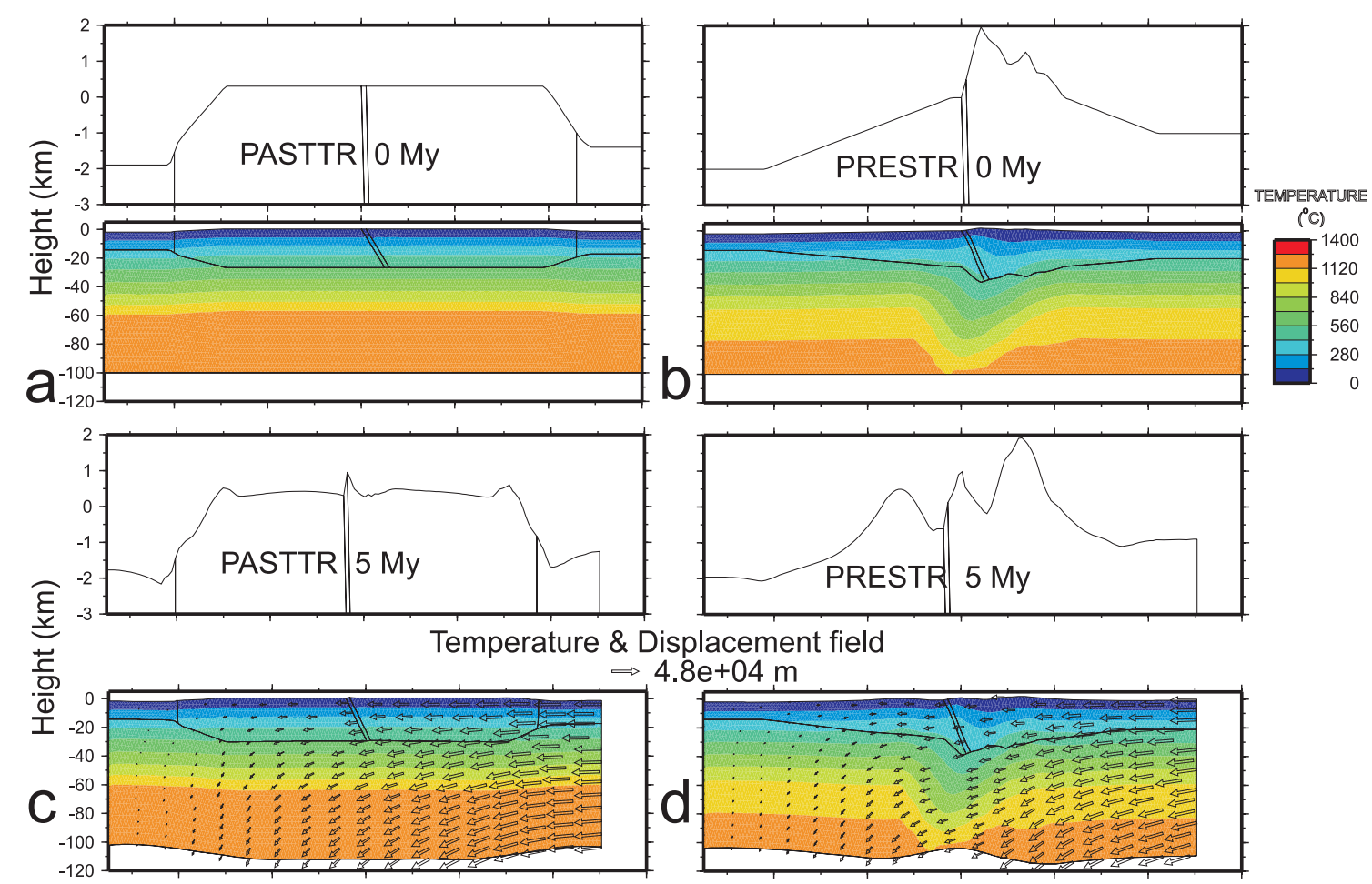

splacement field
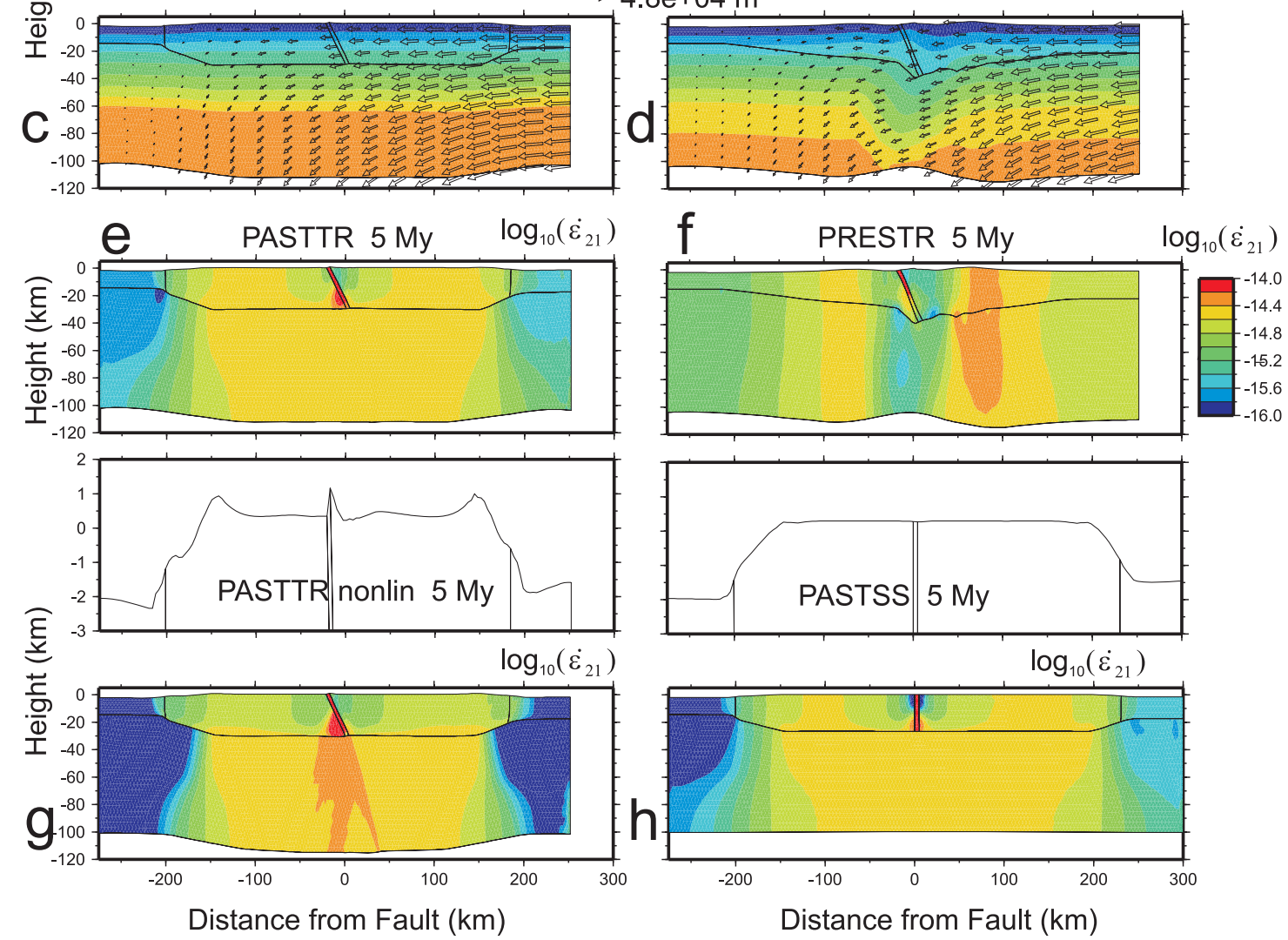

Plate 1. Results of geodynamic modeling. (a). Starting temperature field and structure for experiments with prefix PAST (Table 3). Top panel is topography; bottom panel is a cross section, with $\mathrm{x}=0$ at the surface intersection of the Alpine Fault. (b) Starting temperature field and structure for experiments with prefix PRESTR. (c) Temperature, topography and displacement fields after 5 My of transpression for experiment PASTTR. (d) Temperature, topography and displacement fields after 5 My of transpression for experiment PRESTR. (e) Shear strain rate $\log _{10}\left(\varepsilon_{21}\right)$ where 1 and 2 are horizontal and vertical Cartesian coordinates, respectively, for experiment PASTTR after 5 My of transpression (f) Same for experiment PRESTR after 5 My. (g) Shear strain rate and topography for experiment PASTTRnonlin after 5 My (h) Same for experiment PASTSS after 5 My. 
or directly beneath it. Strain localization is much weaker in the mantle. Strain is enhanced in the mantle underneath the continent compared to the adjacent oceanic mantle, but it is nearly constant across the width of the continental region. Non-linear models display slightly higher shear strains in a $50 \mathrm{~km}$ wide domain beneath the Alpine fault. However, only small mountains are being formed near the Alpine Fault, and no localized cold mantle root has developed, despite deformation having occurred for $5 \mathrm{My}$. The shear strain for pure strike-slip deformation (model PASTSS) is similar to that for transpression (Plate 1).

The temperature distribution after $5 \mathrm{My}$ of deformation in the present geometry experiments (PRESTR) shares similar features to PASTTR; isotherms under the continent have been broadly depressed compared to the temperature field at 0 My (Plate 1). The strain field, however, is markedly different from the strain field for experiment PASTTR. The cold root remains relatively undeformed due to the strong temperature dependence of viscosity and the major deformation is localized in the continental lithosphere that borders the thickened fault domain. This causes mountains as high or higher than the Southern Alps to develop on both coasts and thickened lithosphere to form beneath these mountains. In contrast, the cool lithosphere under the Alpine Fault in experiment PASTTR does not deform or thicken as much as that at the edges. This experiment is therefore not consistent with present deformation. Liu and Bird [2006] find similar growth of mountains east $\&$ west of South Island when a lithospheric root is present without an embedded weak zone.

Including nonlinear dependence of stress on strain localizes the deformation for experiment PASTTRnonlin more strongly beneath the continental landmass (Plate 1), but still not enough to explain the formation of the present crustal root beneath the Alpine Fault, for which a strong localization of the horizontal shortening along the fault is necessary [e.g., Norris and Cooper, 2003; Beavan et al., 2006]. Splitting patterns computed for these experiments are shown in Figure 2. For all PAST experiments, the delay times in the oceanic regions are small $(<0.3 \mathrm{~s})$, and, where they are determinable, the fast polarizations are close to $-45^{\circ}$ from the Alpine Fault strike (which is $0^{\circ}$ ). The patterns are as expected for small shear strains: olivine [100] axes and hence the fast polarization of S-waves align with the extension direction, but the anisotropy is very weak. Under the continent, the delay times are over $0.5 \mathrm{~s}$, and the larger strain aligns fast orientations closer to fault parallel $\left(-40^{\circ}\right.$ to $-25^{\circ}$ ), but not as close as the measured values in the central Southern Alps (Figure 1). Yet all the PAST experiments show relatively consistent fast polarizations and delay times across the continental region, in agreement with the SKS measurements (Figure 1) [e.g., Klosko et al., 1999; Duclos et al., 2005]). Nonlinear models show somewhat stronger anisotropy localization than the linear models, as evidenced by fast polarizations more strongly fault-parallel and larger delay times toward the Alpine Fault.

The cold root in both linear and nonlinear experiments PRESTR and PRESTRnonlin inhibits strain beneath the fault, so that splitting varies strongly across the continental region, with fast polarizations at about $-45^{\circ}$ to the fault plane and small delay times in the centre of the region above the root (Figure 2). Away from the root, delay times approach those of the PASTTR experiments.

The splitting predictions in the experiments starting from the present structure (PRES) are very different from the measured splitting values. In contrast, splitting predictions from the PAST experiments are quite similar to measured values, suggesting that the present anisotropy can be fully explained by olivine LPO formed in the lithosphere during an earlier phase of deformation. Because the relative plate motion during the period from $\sim 45$ to $10 \mathrm{Ma}$ was nearly parallel to the Alpine Fault, we examine the strain and the shear wave splitting expected from such a deformation (Figure 3 ). We show only the nonlinear cases here. We examine both a $100 \mathrm{~km}$ thick (PASTSSnonlin) and $200 \mathrm{~km}$ thick (PASTSSdeepnonlin) model. The strain is similar to that for the experiment PASTTRnonlin (Plate 1). The splitting is also similar, showing a rotation over time of the fast polarizations above the continental region to becoming progressively more faultparallel (Figure 3). Both depth ranges show similar fast polarizations at similar times (compare 6 My values). Linear models yield nearly constant polarizations across most of the continental regions, while nonlinear models are closer to fault-parallel over the fault (Figures 2,3). By $40 \mathrm{My}$, the fast polarizations are closer than $15^{\circ}$ to the fault-plane. The delay times increase until about $15 \mathrm{My}$, at which point they saturate, yielding the same delay time regardless of increasing strain, even though the fast polarizations continue to rotate. For the $200 \mathrm{~km}$ thick experiment, the delay times are about twice as large because they travel through more anisotropic material, reaching $2.3 \mathrm{~s}$. The fast polarizations take longer to become fault-parallel in the deep (200 km thick) model experiment compared to the $100 \mathrm{~km}$ thick experiment (for example, the fast polarizations at $20 \mathrm{My}$ in the deep experiment are similar to those at $15 \mathrm{My}$ in the $100 \mathrm{~km}$ thick experiment), because the strain is spread across a thicker region and is therefore somewhat weaker.

The experiments discussed so far have included constant densities of $2800 \mathrm{~kg} / \mathrm{m}^{3}$ in the crust and $3300 \mathrm{~kg} / \mathrm{m}^{3}$ in the mantle. However, these simplified experiments were not able to produce the present lithospheric structure by starting from the inferred past deformation. For example, experi- 

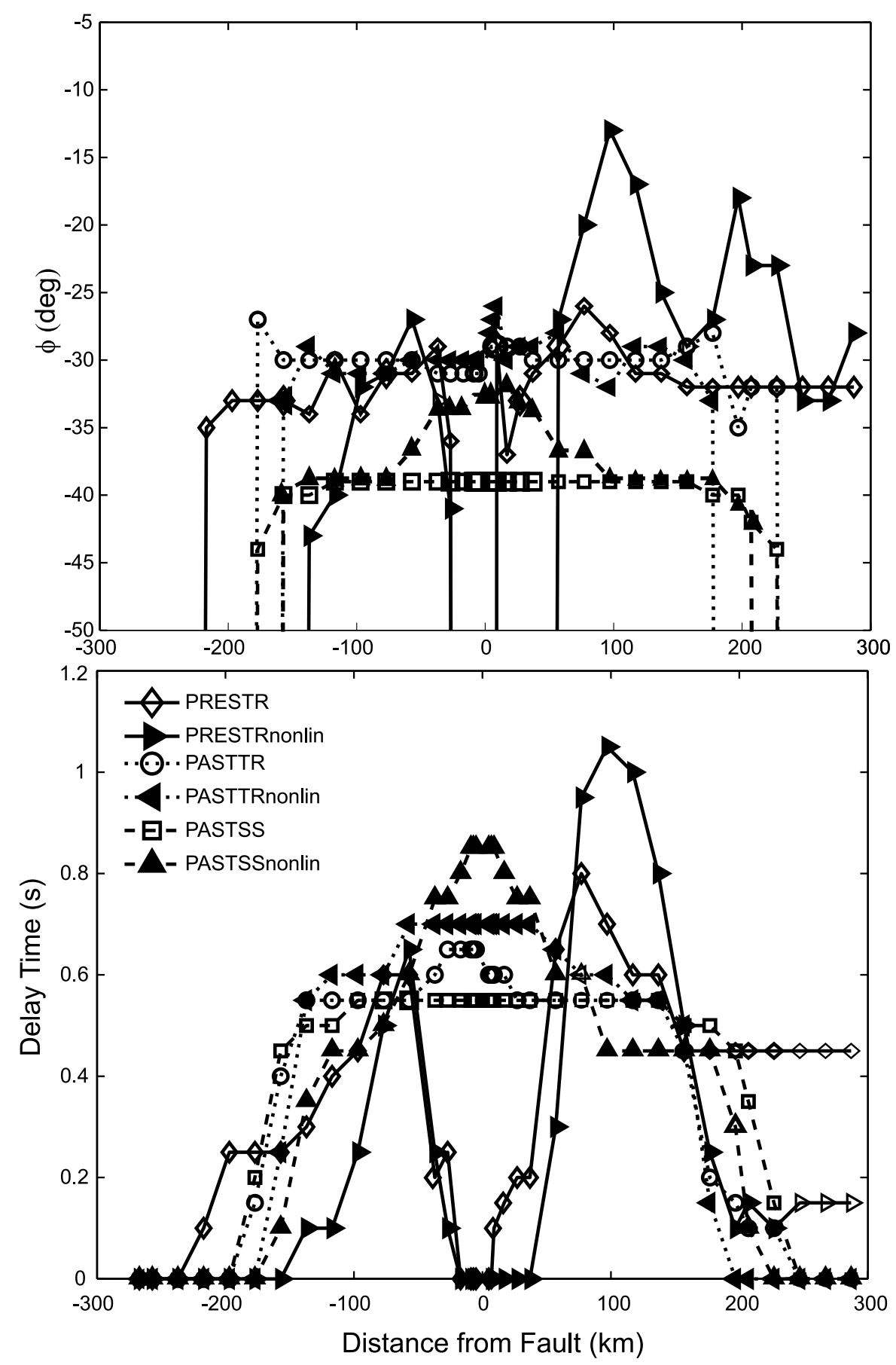

Figure 2. Modeled splitting parameters as a function of horizontal distance from the surface trace of the Alpine Fault, for model times of $6 \mathrm{My}$. Top: Fast polarization, measured relative to the strike of the Alpine Fault at $0^{\circ}$; e.g., $-30^{\circ}$ means that the fast polarization is $30^{\circ}$ clockwise from the strike of the Alpine Fault. Bottom: Delay time. Experiment names (Table 3) are given in the key. Color version of this figure is on CDROM which accompanies this volume. 

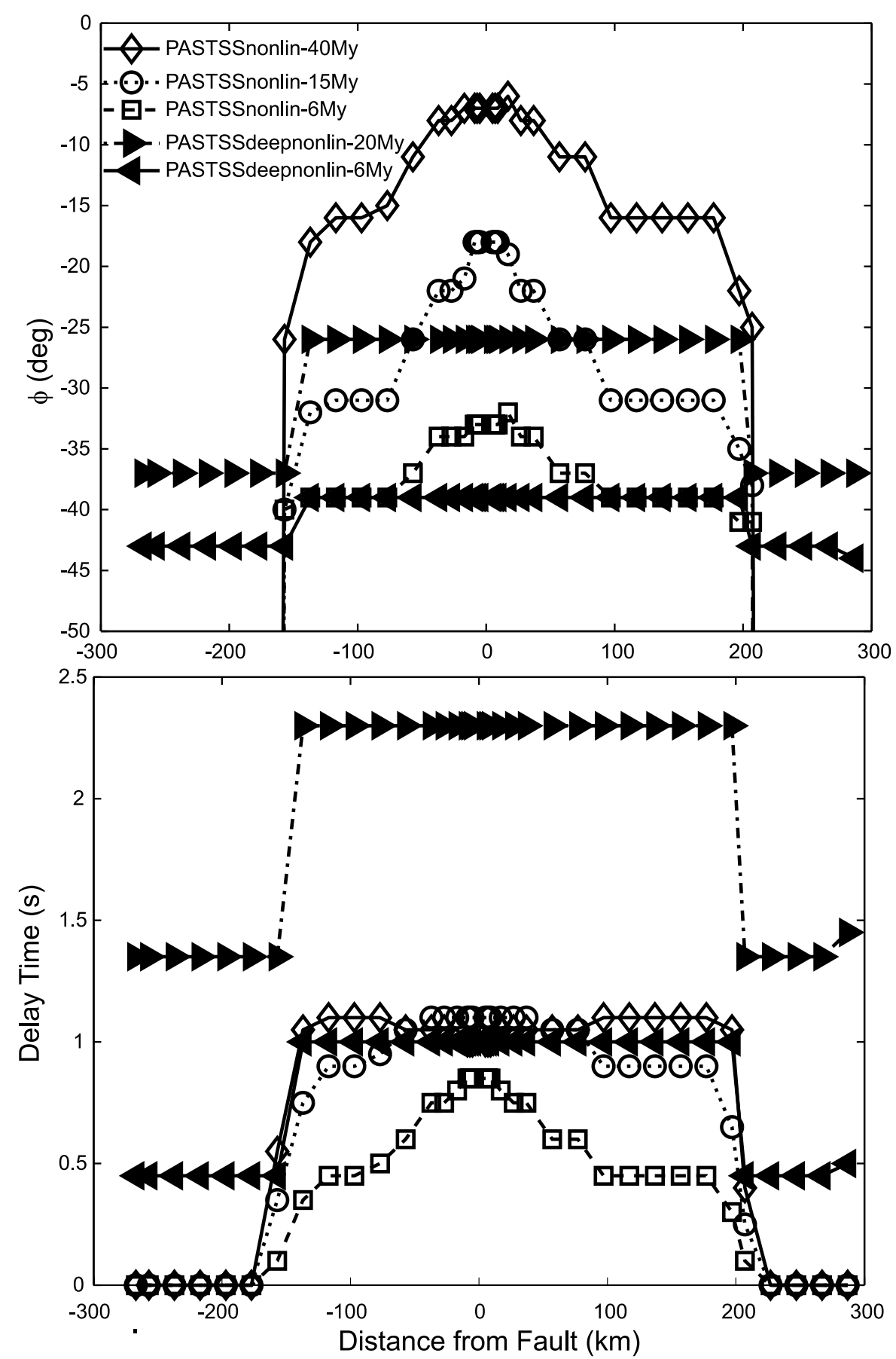

Figure 3. Splitting measurements as a function of distance from the fault for nonlinear experiments PASTSSnonlin and PASTSSdeepnonlin for various time intervals. Note that the delay times saturate by $15 \mathrm{My}$ for the experiment with lithosphere thickness of $100 \mathrm{~km}$. Color version of this figure is on CDROM which accompanies this volume. 
ments PASTTR and PASTRnonlin yielded a broad down warp of the mantle, but not a concentrated root, despite running for 5 My (Plate 1). As temperature-dependent density is expected to play a role in the formation of such crustal roots via Rayleigh-Taylor instabilities [e.g., Houseman and Molnar, 1997; Molnar et al., 1998]), we modified the program to test whether temperature- and depth-dependence of the density alters the solution, as described in the methods section. The experiments shown here do not include erosion, and also include a weak zone under the continents, because the weak zone resulted in a stronger response to the density structure.

As expected, the cold lithospheric root in the present (PRES) experiment deepens when temperature-dependent density is included (Plate 2, experiment PRESTRdensdeep). Because erosion is not included, the compressional component of motion causes the crustal root to thicken further. When erosion is included (not shown), the crustal root maintains a more constant thickness, with material loss through the surface erosion. There is also more upward flow of material near the surface when erosion is included. The surface elevation in both experiments is brought down by the pull of the cold lithospheric root, and both experiments have shear deformation concentrated away from the cold root region. Nonlinear versions of the deep models became unstable before the linear models, and so are not shown in Plate 2 although they were used to calculate splitting in Figure 4.

The PAST model experiment that most closely evolves into the present-day configuration of central South Island when transpressional boundary conditions were applied, was when we included a narrow weak zone in the mantle beneath the fault (Plate 2, experiment PASTTRdens). The lithosphere in the weak region thickened more than the surrounding regions, making it closer to the present lithospheric structure inferred from P delays [Stern et al., 2000]. Weakening in this domain may result from a large variety of strain dependent processes, such as development of mechanical anisotropy due to the progressive orientation of olivine crystals in easy glide positions [Tommasi et al., 2000] or reduction in grain size due to dynamic recrystalization. Erosion was not included in this case, but is expected to have little effect because the surface remains low in elevation. Predicted splitting from the PASTTRdens experiments shows a variation of delay time and fast polarization with distance from the fault (Figure 4). The strong variation in the fast polarization in the centre of the PRESTRdensdeep experiment is caused by the plunging of the axes of symmetry of olivine when the motion in the "drip" becomes vertical. The observed $\phi$ and dt do not vary as a function of distance from the Alpine Fault (Figure 1), and are thus inconsistent with this experiment.

\section{DISCUSSION}

All the experiments show the highest strain rates underneath the continental landmass. The rates are not highest at the border between continental and oceanic crust (the two types of crust are not distinguished compositionally in our models). Instead the rates are highest where the temperatures are hottest and therefore the viscosities are lowest; in these models the hottest temperatures are under the continental crust. While most measurements of anisotropy in New Zealand are on continental material and hence cannot test the prediction that higher strain-rates occur beneath continental cf. oceanic crust, there are a few measurements close to the margin that do suggest a decrease in anisotropy where the continental crust decreases in thickness. The limits of anisotropy determined by Pn measurements along SIGHT line T2 [Scherwath et al., 2002; Baldock and Stern, 2005], occur above the $1000 \mathrm{~m}$ bathymetric contour (Figure 1). These authors found that the wave speeds along line $T 2$ were small under the continent compared to the much larger values along perpendicular lines, which led them to infer high anisotropy in South Island upper mantle just east of the Alpine Fault. The wave speeds increased to more average mantle speeds at the points marked by large arrows in Figure 1 , which led them to suggest that the anisotropy decreased at these points. Similar arguments suggested a smaller region of anisotropy along line T1 [van Avendonk et al., 2004]. In addition, station JACA, the southernmost station on the Australian Plate in the SAPSE deployment, is close to oceanic crust, and yielded very little anisotropy (Figure 1). Single events at JACA yielded only null measurements, and the stacked values yielded $0.6 \mathrm{~s}$ delay time, the smallest of all South Island stations [Klosko et al., 1999]. The Fresnel zone radius at the surface for SKS phases is about $40 \mathrm{~km}$, and includes oceanic material deeper than $1000 \mathrm{~m}$. This suggests the $1000 \mathrm{~m}$ bathymetry line may represent the edge of the continental crust and therefore the edge of the region of high anisotropy.

In all the experiments with the present temperature structure, shear strain maxima occurred away from the cold root. Calculated shear-wave splitting for the strain from these experiments yielded both fast polarizations and delay times that varied substantially with distance from the fault, contrary to the measured values. The models simulate a simplified time evolution of the plate boundary motion, and a model could be devised in which rheology weakens in a direct tradeoff with thickening, such that the strain and resulting anisotropy would be more consistent across the continent with the present temperature and structure. However, there was a long period (at least $20 \mathrm{My}$ ) of strike-slip motion, with significant strain accumulation, before the onset of compressional motion 


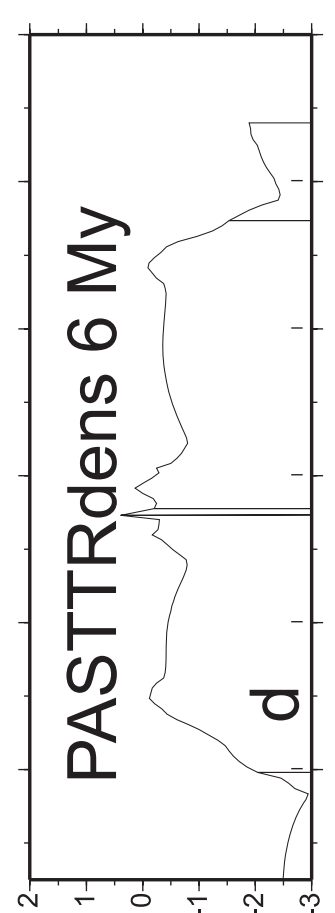

(ux) $+46 !$

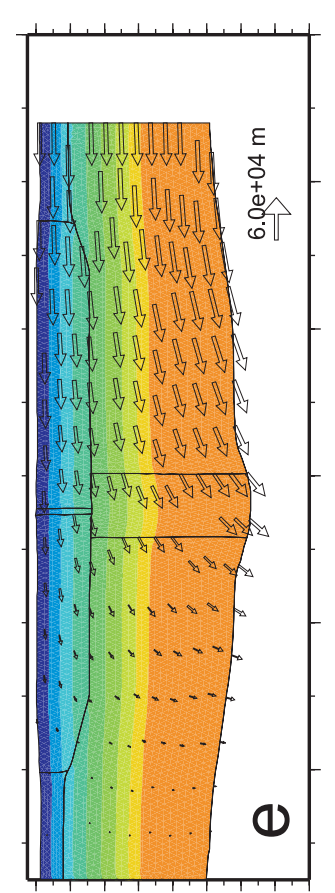

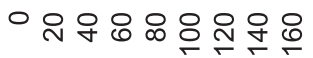
(ur) प1dә0
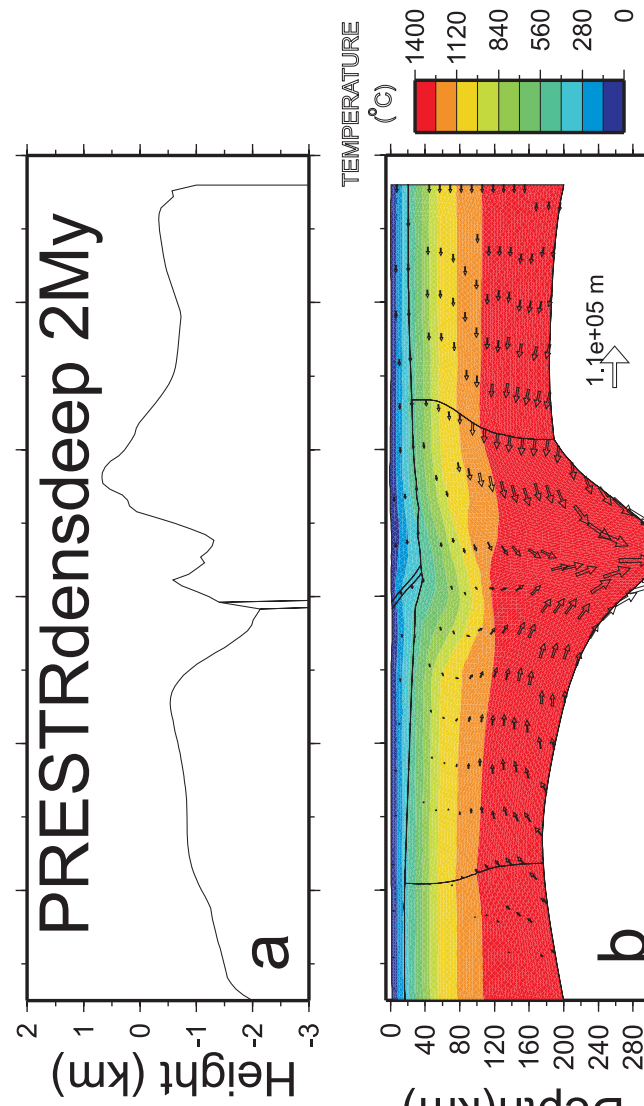

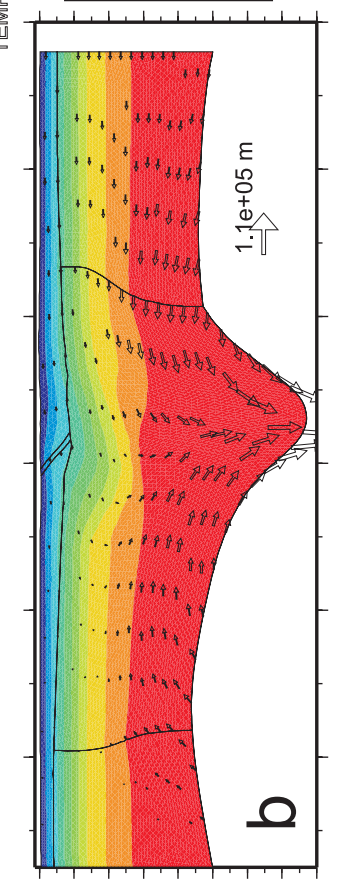

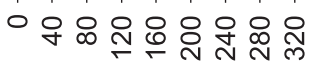
(uy)yłdə0

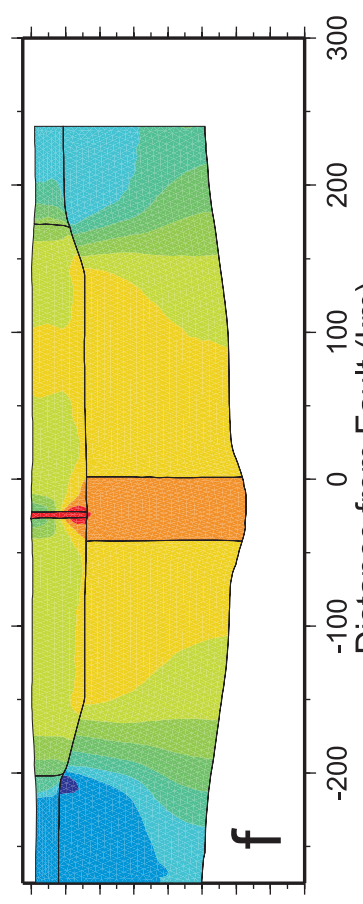

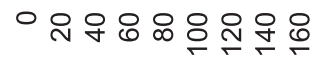
(uy) प1dә0

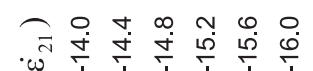

.

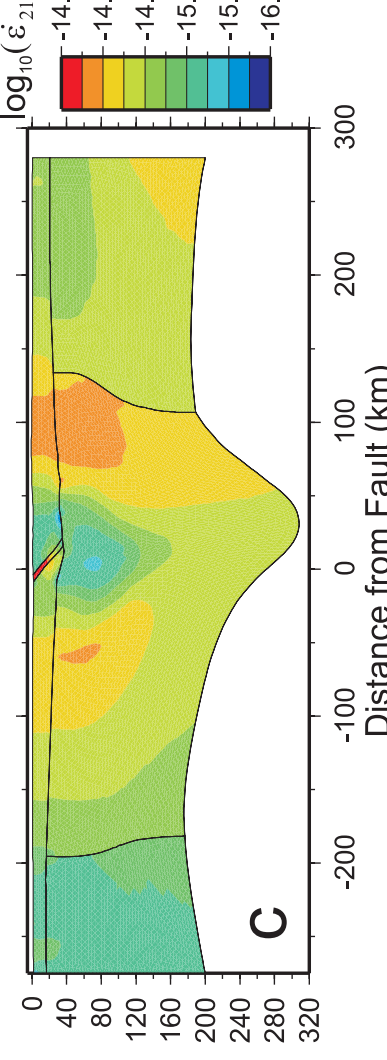

(uY)पाdə0

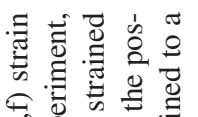

of

के

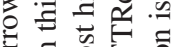

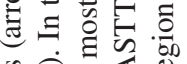

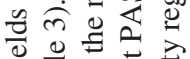

过菏

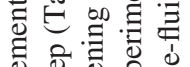

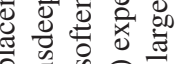

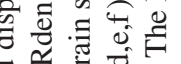

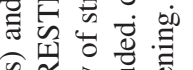

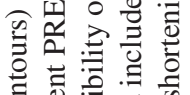

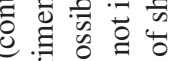

o

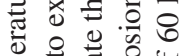

员

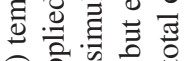

(1) ते

$\therefore$ 定离

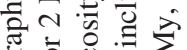

क्ष 0.06

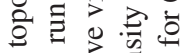

ช。

$\dot{0}$ 월

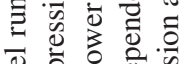

은

छ

Ð $0 . \stackrel{0}{0}$

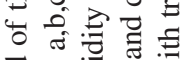

ฮี

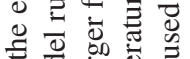

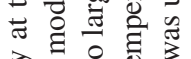

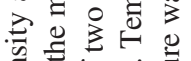

चै

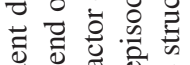

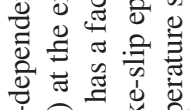

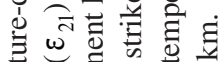

苾

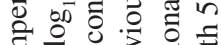

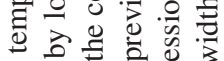

论

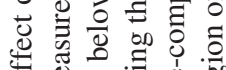

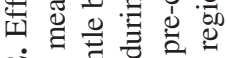

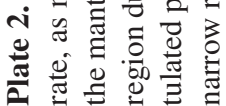



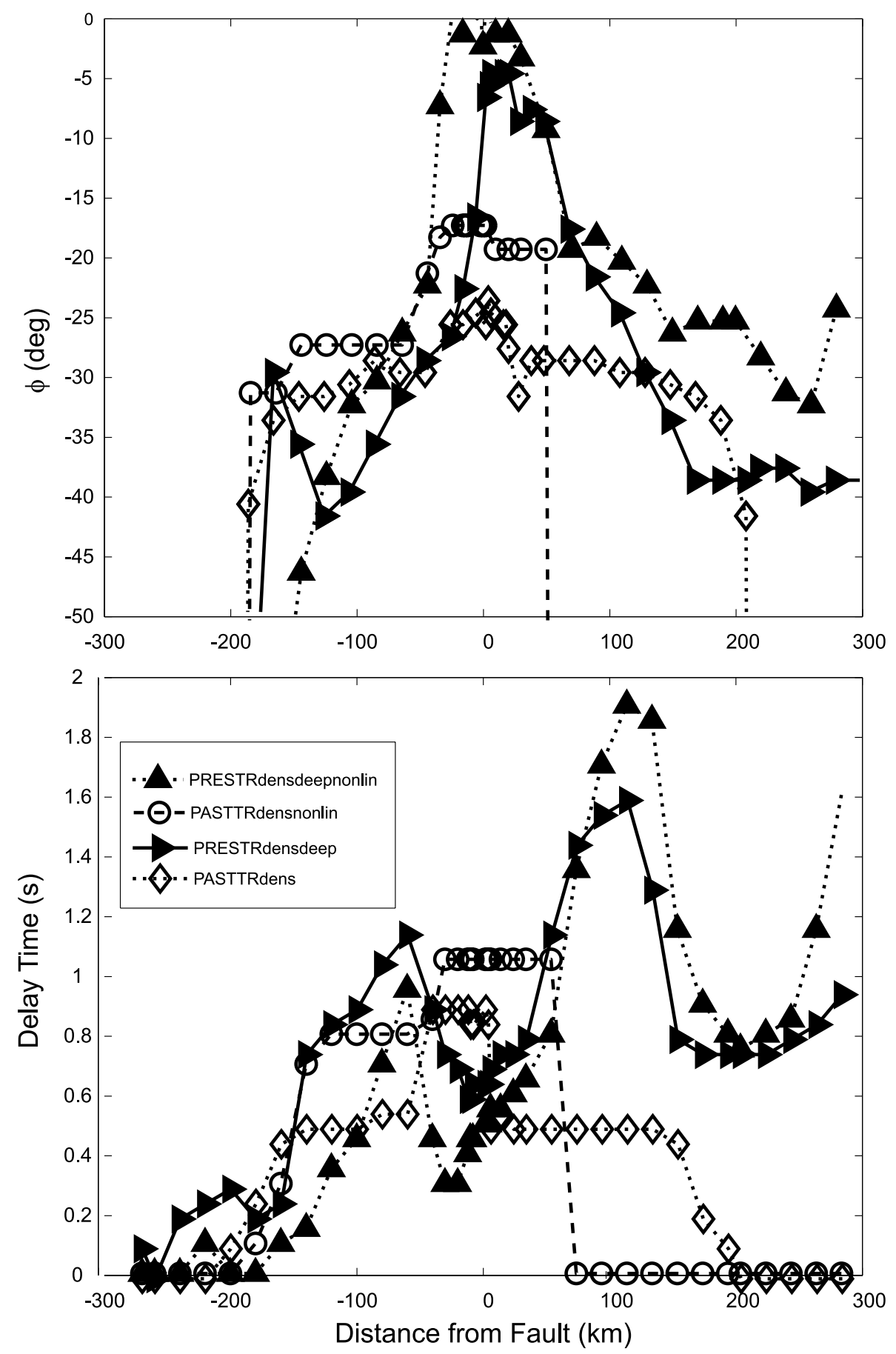

Figure 4. Splitting values for the models shown in Plate 2, and their nonlinear counterparts. Top: Splitting fast polarization as a function of distance from the fault. Bottom: Delay time as a function of distance from the fault. Experiment names (Table 3) are given in the key. The experiments all predict patterns of fast polarizations and delay times that vary with distance from the fault. Color version of this figure is on CDROM which accompanies this volume. 
that most likely formed the present temperature structure [Walcott, 1998; Cande and Stock, 2004]. Our modeling shows that such significant strike-slip strain can produce anisotropy splitting parameters that can match the present-day shear-wave splitting measurements. This is consistent with the view that at least a large part of the anisotropy measured today is due to past deformation during the previous pure strike-slip episode, before the cold root was formed.

The LPO models we calculate start with isotropic, unstrained aggregates and build up strain and LPO over time. In the real earth, deformations are built on top of previous ones. This means that an LPO developed during previous strikeslip deformation could dominate the present-day LPO. This is particularly the case for the cool lithospheric root that is thought to have formed during the later, transpressional phase. We expect superposition of strain during the two phases, with smaller strain in the lithospheric root in the transpressional phase once it cooled and became stronger than surrounding material, would preserve the strike-slip olivine LPO in the root. Possibly the material further from the fault would strain more strongly, and become more fault-parallel over time than the material directly under the fault. However, the error bars in the splitting measurements available now are too large to distinguish between these possibilities.

If anisotropy formed in a previous episode of strike-slip deformation, then SKS measurements cannot be used to distinguish between end-member models for mantle deformation of central South Island, such as inferred subduction of Pacific or Australian mantle along a localized "antifault" [e.g., Wellman, 1979] vs. distributed thickening of mantle lithosphere over hundreds of kilometers [e.g., Molnar et al., 1999]. Moreover, the unrealistic topography developed for the symmetric cold root model both herein, and in Liu and Bird [2006], suggests that if such a root is present, it is likely to have been formed in a previously weakened region. Previous models that have investigated evolution of the lithosphere beneath South Island [Pysklywec, 2002; Gerbault, 2003] have shown that an embedded weak zone can initiate deformation in the upper mantle along a dipping shear plane, which acts to localize crustal deformation and can explain both the topographic uplift of the Southern Alps, and development of a crustal root. The results here, including the "negative" result in which we were unable to reproduce current South Island dynamics with a homogeneous mantle rheology, also suggest that some variation in mantle strength is necessary. More localized mantle deformation at present is also supported by geodetic measurements of strain currently accumulating across central South Island [e.g., Beavan et al., 2006; Ellis et al., 2006; Wallace et al., 2007].

For the strike-slip motion without a root, the delay times increase until about $15 \mathrm{My}$, at which point they saturate, yielding the same delay time regardless of increasing motion (Figure 3). The average delay time measured for central South Island stations is $1.4 \mathrm{~s}$ [Duclos et al., 2005]. This is higher than the $1.0 \mathrm{~s}$ to which the delay times over the continental regions saturate with our $100 \mathrm{~km}$ thick experiments after $15 \mathrm{My}$, but smaller than the $2.3 \mathrm{~s}$ delay time to which our $200 \mathrm{~km}$ thick lithosphere experiments saturate. This suggests either that the lithospheric thickness is between 100 and $200 \mathrm{~km}$, or that another mechanism has allowed anisotropy to be smaller or larger than that modeled.

Although the delay times saturate, the fast polarizations continue to rotate to become more fault-parallel with time, i.e., increasing strain. This may explain the variations observed between southern and central South Island, in which the fast polarization measured in the southern region is consistent with the extension direction determined by the surface strain measurements [Little et al., 2002], with an orientation further away from fault-parallel in the south than in the central region, but with delay times nearly constant despite the smaller strain. The measured splitting along central South Island is closer to fault-parallel than the calculated splitting, even after 40 My of movement of the input strain, which yields $1400 \mathrm{~km}$ of displacement, greater than the $850 \mathrm{~km}$ measured [Sutherland, 1999]. $850 \mathrm{~km}$ displacement equates to $23 \mathrm{My}$ in our experiments, yielding $\phi$ about 25 degrees from fault-parallel (Figure 2 and 3). Thus, to explain the nearly fault-parallel fast polarizations observed along the central Alpine Fault, we need to consider that additional deformation mechanisms, such as dynamic recrystallization, accelerate the development of olivine LPO, leading olivine [100] axes to align with the shear direction at shear strains of 1 , as observed in simple shear deformation experiments[Zhang and Karato, 1995; Bystricky et al., 2000]. Nevertheless the splitting from the present experiments matches better to the measurements than those determined by simpler 2D modeling [Savage et al., 2004]. This is because the delay times in the experiments shown here saturate with fairly small strains, less than $525 \mathrm{~km}$ displacement or slightly over 1, taking the strain rate of $10^{-14.5} \mathrm{~s}^{-1}$ (Plate 1) over $15 \mathrm{My}$. Thus, delay times are similar across the continental region despite differences in strain and fast polarization. Another major difference between the present experiments and the earlier study is in the boundary conditions. In the earlier study, the plate motion was driven from above, i.e., a prescribed velocity was set at the surface in opposite directions on the two sides of a fault, and the bottom boundary was fixed to zero slip at great depth. In that case, the strain decreases with distance from the fault, both in depth and laterally. The integrated effect of the anisotropy with depth was to weaken the splitting that would have been observed if the surface strain extended to all depths. In the models shown here, plate motion was 
driven from the side, and the bottom boundary was free-slip. This allowed the strain to be similar at all depths (e.g., Plates 1,2). The seismic waveforms therefore encounter similar anisotropy through their entire path, allowing large delay times and consistent polarizations to be measured. Lateral variations in Pn anisotropy [Baldock and Stern, 2005] and shear wave splitting from local earthquakes [Audoine et al., 2000] both suggest that the deformation might be smaller in the uppermost mantle than in the region sampled by the SKS phases, suggesting that the true conditions in the Earth might be in between the boundary conditions examined in these two studies.

The coherence of SKS between the southern North Island and South Island suggests a common cause. If so, there are two possibilities. Both regions may be affected by current, trench-parallel asthenospheric flow or by past strike-slip strain such as modeled here. We discuss the possibilities more fully in a review paper in this volume [Savage et al., 2007].

\section{SUMMARY}

a) The out-of-plane geodynamic experiment results that start from pre-collisional conditions (PAST) predict that thick continental crust localizes the strain beneath the continental compared to the oceanic regions, but the strain is distributed throughout the continental region. Shear-wave splitting parameters for pure strike-slip deformation through such a region yield delay times that saturate at a maximum value of $1.0 \mathrm{~s}$ to $2.3 \mathrm{~s}$ for lithospheric thicknesses of 100 and $200 \mathrm{~km}$, respectively, across most of the continental region. The fast polarizations are constant across the region but rotate with increasing strain to become more fault-parallel, reaching $25^{\circ}$ at the maximum expected strains. The measured delay time average of $1.4 \mathrm{~s}$ suggests lithosphere either greater than 100 $\mathrm{km}$ thick, or more anisotropic than modeled. Dynamic recrystallization, leading to faster orientation of olivine [100] parallel to the shear direction, may be needed to explain the fault-parallel splitting fast polarizations in the central Alpine Fault, and could also cause larger anisotropy than modeled, helping to fit the delay times.

b) Experiments starting from the present-day configuration (PRES) and no weak zone in the mantle predict that a cold root should inhibit strain and therefore the formation of anisotropy. Such experiments have difficulty reproducing observed shear wave splitting and topography. A weak zone within the mantle that localizes deformation there is necessary to reproduce current deformation patterns, in which case mantle anisotropy accumulates in a narrow region. Therefore, it is likely that the present wide-spread anisotropy was formed during the previous episode of strike-slip deformation, before the cold root was formed. c) We predict that the upcoming ocean bottom seismometer deployment off the coasts of South Island will find anisotropy changes at the edge of the continental crust (i.e., the regions where the bathymetry deepens in Figure 1), similar to what has already been inferred for the Pn anisotropy along SIGHT line T2.

Acknowledgements. Karen Fischer allowed us to modify her codes for the splitting calculations. Financial support was supplied by the NZ Marsden Fund and the NZ Foundation for Research, Science and Technology. The research was begun while M. Savage was on sabbatical leave at the University of Montpellier II, with support from Victoria University and from the Centre National de la Recherche Scientifique (France) through a Chercheur étranger associé position. Thorough, constructive reviews by Peter Molnar and Zhen Liu are much appreciated.

\section{REFERENCES}

Audoine, E., M. K. Savage, and K. Gledhill (2000), Seismic anisotropy from local earthquakes in the transition region from a subduction to a strike-slip plate boundary, New Zealand, J. Geophys. Res., 105, 8013-8033.

Babuska, V., and M. Cara (1991), Seismic Anisotropy in the Earth, 217 pp., Kluwer Academic Publishers, Dordrecht/Boston/ London.

Bai, Q., S. J. Mackwell, and D. L. Kohlstedt (1991), Hightemperature creep of olivine single crystals, 1 , Mechanical results for buffered samples, J. Geophys. Res., 96, 2441-2463.

Baldock, G., and T. Stern (2005), Width of mantle deformation across a continental transform: Evidence from upper mantle (Pn) seismic anisotropy measurements, Geology, 33, 741-744.

Beavan, J., S. Ellis, L. Wallace, and P. Denys (Eds.) (2006), Kinematic Constraints from GPS on Oblique Convergence of the Pacific and Australian Plates, Central South Island, New Zealand, in revision pp.

Blackman, D. K., J.-M. Kendall, P. R. Dawson, H.-R. Wenk, D. Boyce, and J. P. Morgan (1996), Teleseismic imaging of subaxial flow at mid-ocean ridges: travel-time effects of anisotropic mineral texture in the mantle, Geophys. J. Int., 127, 415-426.

Bourguignon, S., T. A. Stern, and M.K. Savage (2007), Crust and mantle thickening beneath the southern portion of the Southern Alps, New Zealand, Geophys. J. Int., 168, 681-690

Bystricky, M., K. Kunze, L. Burlini, and J.-P. Burg (2000), High shear strain of olivine aggregates: rheological and seismic consequences, Science, 290, 1564-1567.

Cande, S. C., and J. M. Stock (2004), Pacific-Antarctic-Australia motion and the formation of the Macquarie Plate, Geophys. J. Int., 157, 399-414 doi:310.1111/j.1365-1246X.2004.02224.X.

Chéry, J., M. D. Zoback, and S. Hickman (2004), A mechanical model of the San Andreas fault and SAFOD pilot hole stress measurements, Geophys. Res. Lett., 31, doi:10.1029/2004GL019521. 
Chopra, P. N., and M. S. Paterson (1984), The role of water in the deformation of dunite, J. Geophys. Res., 89, 7861-7876.

Cundall, P. A. (1988), Formulation of a three-dimensional distinct element model; Part I, A scheme to detect and represent contacts in a system composed of many polyhedral blocks International Journal of Rock Mechanics and Mining Sciences \& Geomechanics Abstracts, 25, 107-116.

Duclos, M. (2005), Insights on Plate Boundary Deformation from Seismic Anisotropy in the New Zealand Upper Mantle, 210 pp, Victoria University of Wellington, Wellington, New Zealand.

Duclos, M., M. K. Savage, A. Tommasi, and K. R. Gledhill (2005), Mantle Tectonics beneath New Zealand Inferred from SKS Splitting and Petrophysics, Geophys. J. Int., 163, 760-774, doi:710.1111/j.1365-1246X.2005.02793.x.

Ellis, S., J. Beavan, and D. Eberhart-Phillips (2006), Bounds on the width of mantle lithosphere flow derived from surface geodetic measurements: application to the central Southern Alps, New Zealand, Geophysical Journal International, doi: 10.1111/ j.1365-1246X.2006.02918.x.

Fischer, K. M., E. M. Parmentier, A. R. Stine, and E. R. Wolf(2000), Modeling anisotropy and plate-driven flow in the Tonga subduction zone back arc, J. Geophys. Res., 105, 16,181-16,192.

Gerbault, M., Henrys, S., and Davey, F.J. (2003), Numerical models of lithospheric deformation forming the Southern Alps of New Zealand, J. Geophys. Res., 108, 2341: doi:2310.1029/ 2001JB001716.

Houseman, G. A., and P. Molnar (1997), Gravitational (RayleighTaylor) instability of a layer with non-linear viscosity and convective thinning of continental lithosphere, Geophys. J. Int., 128, $125-150$

Kennett, B. L. N., E. R. Engdahl, and R. Buland (1995), Constraints on seismic velocities in the Earth from traveltimes, Geophys. $J$. Int., 122, 108-124.

Klosko, E. R., F. T. Wu, H. J. Anderson, D. Eberhardt-Phillips, T. V. McEvilly, E. Audoine, M. K. Savage, and K. R. Gledhill (1999), Upper mantle anisotropy in the New Zealand region, Geophys. Res. Lett., 26, 1497-1500.

Kohler, M. D., and D. Eberhart-Phillips (2002), Three-dimensional lithospheric structure below the New Zealand Southern Alps, $J$. Geophys. Res., 107, 2225, doi:2210.1029/2001JB000182.

Kreemer, C., W.E. Holt, and A. J. Haines (2003), An integrated global model of present-day plate motions and plate boundary, Geophys. J. Int., 154, 8-34.

Kumazawa, M., and D. L. Anderson (1969), Elastic moduli, pressure derivatives, and temperature derivatives of single-crystal olivine and single-crystal forsterite, J. Geophys. Res., 74, 59615972.

Lebensohn, R. A., and C. N. Tomé (1993), A self-consistent anisotropic approach for the simulation of plastic deformation and texture development of polyscrystals: application to zerconion alloys, Acta Metall. Mater., 41, 2611-2624.

Leroy, Y., and M. Ortiz (1989), Finite element analysis of strain localization in frictional materials, Int. J. Numer. Anal. Methods Geomech., 13, 53-74.

Little, T. A., M. K. Savage, and B. Tikoff (2002), Relationship between crustal finite strain and seismic anisotropy in the mantle,
Pacific-Australia plate boundary zone, South Island, New Zealand, Geophys. J. Int., 151, 106-116.

Liu, Z., and P. Bird (2006), 2-D and 3-D finite element modeling of mantle processes beneath central South Island, New Zealand, Geophys. J. Int., 165, 1003-1028.

Mainprice, D. (1990), A FORTRAN program to calculate seismic anisotropy from lattice preferred orientation of minerals, Comput. Geosci., 16, 385-393.

Molnar, P., H. Anderson, E. Audoine, D. Eberhart-Philips, K. Gledhill, E. Klosko, T. McEvilly, D. Okaya, M. Savage, T. Stern, and F. Wu (1999), Continuous deformation versus faulting through the continental lithosphere of New Zealand, Science, 286, 516-519.

Molnar, P., G. A. Houseman, and C. P. Conrad (1998), RayleighTaylor instability and convective thinning of mechanically thickened lithosphere: effects of non-linear viscosity decreasing exponentially with depth and of horizontal shortening of the layer, Geophys. J. Int., 133, 568-584.

Moore, M., P. England, and B. Parsons (2002), Relation between surface velocity field and shear-wave splitting in the South Island of New Zealand, J. Geophys. Res., 107, 2198, doi:2110.1029/ 2000JB000093.

Norris, R. J., and A. F. Cooper (2001), Late Quaternary slip rates and slip partitioning on the Alpine Fault, New Zealand J. Structural Geol., 23, 507-520.

Norris, R. J., and A. F. Cooper (2003), Very high strains recorded in mylonites along the Alpine Fault, New Zealand; implications for the deep structure of plate boundary faults., Journal of Structural Geology, 25, 2141-2157.

Paterson, M. S., and F. C. Luan (1990), Quartzite rheology under geological conditions, in Deformation mechanisms, rheology and tectonics edited by R. J. R. Knipe, E H pp. 299-307, Geological Society Special Publications, Leeds, United Kingdom.

Pysklywec, R. N., Beaumont, C., and Fullsack, P. (2002), Lithospheric deformation during the early stages of continental collision: Numerical experiments and comparison with South Island, New Zealand, J. Geophys. Res., 107, doi:10.1029/2001JB000252.

Savage, M. K. (1999), Seismic anisotropy and mantle deformation: what have we learned from shear wave splitting?, Rev. Geophys. $37,65-106$.

Savage, M. K., M. Duclos, and K. A. Marson-Pidgeon (2007), Seismic anisotropy in the South Island, New Zealand, this volume.

Savage, M. K., K. M. Fischer, and C. E. Hall (2004), Strain modelling, seismic anisotropy and coupling at strike-slip boundaries: Applications in New Zealand and the San Andreas Fault, in Vertical Coupling and Decoupling in the Lithosphere, edited by J. Grocott, Tikoff, B., McCaffrey, K. J. W. \& Taylor, G., pp. 9-40, Geological Society of London, Special Publication, London.

Scherwath, M., T. Stern, F. Davey, D. Okaya, W. S. Holbrook, R. Davies, and S. Kleffmann (2003), Lithospheric structure across oblique continental collision in New Zealand from wide-angle P wave modeling J. Geophys. Res., 108, 18 pp., doi:10.1029/ 2002JB002286.

Scherwath, M., T. Stern, A. Melhuish, and P. Molnar (2002), Pn anisotropy and distributed upper mantle deformation associated 
with a continental transform fault, Geophys. Res. Lett., 29, 16-1116-14, doi:10.1029/2001GL014179.

Shi, Y., R. Allis, and F. Davey (1996), Thermal modelling of the Southern Alps, PAGEOPH, 146, 469-501.

Silver, P. G. (1996), Seismic anisotropy beneath the continents: probing the depths of geology, Ann. Rev. Earth Planet. Sci., 24, 385-432.

Silver, P. G., and W. W. Chan (1991), Shear wave splitting and subcontinental mantle deformation, J. Geophys. Res., 96, $16,429-16,454$

Smith, G. P., and G. Ekstrom (1999), A global study of Pn anisotropy beneath continents, J. Geophys. Res., 104, 963-980.

Stern, T., D. A. Okaya, and M. Scherwath (2002), Structure and strength of a continental transform from onshore-offshore seismic profiling of South Island, New Zealand, Earth, Planets, Space, 54, 1011-1019.

Stern, T. A., P. Molnar, D. Okaya, and D. Eberhart-Phillips (2000), Teleseismic $P$ wave delays and modes of shortening the mantle lithosphere beneath South Island, New Zealand, J. Geophys. Res., 105, 21,615-21,631.

Sutherland, R. (1999), Cenozoic bending of New Zealand basement terranes and Alpine Fault displacement: a brief review, N.Z. Joul. Geol. \& Geophys., 42, 295-302.

Tommasi, A., D. Mainprice, G. Canova, and Y. Chastel (2000), Viscoplastic self-consistent and equilibrium-based modeling of olivine lattice preferred orientations: Implications for the upper mantle seismic anisotropy, J. Geophys. Res., 105, 78937908.

Tommasi, A., B. Tikoff, and A. Vauchez (1999), Upper mantle tectonics: three-dimensional deformation, olivine crystalographic fabrics and seismic properties, Earth and Planet. Science Lett, 168, 173-186.
Turcotte, D. L., and G. Schubert (1982), Geodynamics: Applications of Continuum Physics to Geological Problems, 450 pp., John Wiley \& Sons, New York.

van Avendonk, H. J. A., W. S. Holbrook, D. A. Okaya, J. K. Austin, F. Davey, and T. Stern (2004), Continental crust under compression: A seismic refraction study of South Island Geophysical Transect I, South Island, New Zealand, J. Geophys. Res., 109, doi:10.1029/2003JB002790.

Walcott, R. I. (1998), Modes of oblique compression: late Cenozoic tectonics of the South Island of New Zealand., Rev. Geophys., 36, 1-26.

Wallace, L. M., J. Beavan, R. McCaffrey, and K. Berryman (2007), Balancing the plate motion budget in the South Island, New Zealand, using GPS, geological and seismological data, Geophys. J. Int., 168, 332-52; doi:10.111/j-1365.

Wellman, H. W. (1979), An uplift map for the South Island of New Zealand, Bull. Roy. Soc. N.Z., 18, 13-20.

Wenk, H.-R., K. Bennett, G. R. Canova, and A. Molinari (1991), Modelling plastic deformation of peridotite with the self-consistent theory, J. Geophys. Res., 96, 8337-8349.

Zhang, S., and S.-I. Karato (1995), Lattice preferred orientation of olivine aggregates deformed in simple shear, Nature, 375, 774-777.

J. Chery and A. Tommasi, University de Montpellier II, France. S. Ellis, GNS Science, New Zealand.

M. K. Savage, Institute of Geophysics, School of Earth Sciences, Victoria University of Wellington, New Zealand. (Martha .Savage@vuw.ac.nz) 